\title{
Investigation of the inhibition of carbon steel corrosion in hydrochloric acid solutions by domperidone drug
}

\begin{abstract}
The influence of Domperidone on the inhibition of carbon steel (CS) corrosion in $1 \mathrm{M}$ $\mathrm{HCl}$ solutions was studied using weight loss (WL), (EIS) electrochemical impedance spectroscopy, electrochemical frequency modulation (EFM) and potentiodynamic polarization (PP) techniques, as well as thermodynamic calculations to explore the adsorption mechanism of Domperidone. The inhibition efficiency (IE \%) was found to increase with increasing the dose of the Domperidone and with decreasing temperature. The maximum IE\% of $94.9 \%$ was obtained in presence of $1.12 \times 10^{-4} \mathrm{M}$. The inhibition action of Domperidone was explained in terms of adsorption on CS surface. The adsorption process follows Langmuir isotherm and kinetic-thermodynamic model. Thermodynamic and kinetic parameters were calculated and discussed. Polarization tests showed that this drug is of mixed type. Corrosion protection properties of the drug have been inferred from FT-IR spectra and by atomic force microscope (AFM).
\end{abstract}

Volume 5 Issue 5 - 2017

\section{Fouda AS, El Morsi MA, El Mogy T}

'Department of Chemistry, El-Mansoura University, Egypt

2Department of Chemistry, Tanta University, Egypt

Correspondence: Fouda AS, Department of Chemistry, Faculty of Science, El-Mansoura University, El-Mansoura- 35516, Egypt, Tel +2 050 2365730, Fax +2 050 220227I, Email asfouda@hotmail.com

Received: June 27, 2017| Published: July 27, 2017

Keywords: corrosion inhibition, domperidone drug, carbon steel, W, EIS, EFM, AFM, FT-IR

Abbreviations: CS, carbon steel; EIS, electrochemical impedance spectroscopy; EFM, electrochemical frequency modulation; PP, potentiodynamic polarization; IE, inhibition efficiency; AFM, atomic force microscope; SCE, saturated calomel electrode

\section{Introduction}

Carbon steel is the most worldwide utilized material for industrial and domestic applications, because of its good mechanical properties, availability and relatively reasonable cost. $\mathrm{HCl}$ is widely used in various technological processes in industry (e.g. pickling baths, chemical and petrochemical industries). Corrosion of CS is important and expensive and problem in the industries it represents a significant portion of loss as a result of lost production, inefficient operation, and high maintenance. It has been found that one of the best methods of protecting metals against corrosion involves the use of inhibitors which are substances which slow down the corrosion rate. ${ }^{1,2}$ The corrosion protection is a surface process, which involves adsorption of the organic compounds on the metal surface. The adsorption depends mainly on the electronic structure of the molecule. ${ }^{3}$ There is interesting concern about the toxicity of most organic inhibitors which affect living organisms and also poison the environment. ${ }^{4}$ So, there has been increasing search for green inhibitors. Recently, there are several studies carried out on the use of drugs as inhibitors..$^{5-11}$ The drugs are biocompatibility in nature, environmentally acceptable, readily available and a renewable source. Due to bio-degradability, eco-friendliness, low cost and easy availability, the pharmaceutical based chemicals have been tried as inhibitors for metals under different environments.

The main objective here is to investigate the corrosion protection of $\mathrm{CS}$ in $1 \mathrm{M} \mathrm{HCl}$ solution with and without different doses of Domperidone by different chemical and electrochemical techniques. This drug is cheap, non-toxic and eco-friendly as well as possessing different hetero-atoms like $\mathrm{N}$ and $\mathrm{O}$ which make it good corrosion inhibitor. The following Table gives a comparison of \% IE with different investigated extracts (Table $1 \&$ Figure 1 ).
Table I A comparison of \% IE with different investigated extracts

\begin{tabular}{lllll}
\hline Inhibitor (Drug) & Sample & Medium & IE \% & References \\
\hline Penciillin G & Mild steel & $\mathrm{H} 2 \mathrm{SO} 4$ & 73.7 & 12 \\
Penicillin V & Mild steel & $\mathrm{H} 2 \mathrm{SO} 4$ & 63.3 & 13 \\
Cefalexin & Mild steel & $\mathrm{HCl}$ & 67.5 & 14 \\
Ceftriaxone & Mild steel & $\mathrm{HCl}$ & 90 & 15 \\
Cefotaxime & Mild steel & $\mathrm{HCl}$ & 90 & 16 \\
Cefixime & Mild steel & $\mathrm{HCl}$ & 90 & 17 \\
Ceftobiprole & Mild steel & $\mathrm{HCl}$ & 91.2 & 18 \\
Quinoline & Mild steel & $\mathrm{HCl}$ & 88.7 & 19 \\
Dapsone & Mild steel & $\mathrm{HCl}$ & 90.7 & 20 \\
Domperidone & Copper & $3.5 \% \mathrm{NaCl}$ & 92.6 & 21 \\
Domperidone & Carbon steel & $\mathrm{HCl}$ & 94.7 & Our results \\
\hline
\end{tabular}<smiles>O=C1[NH2+]c2cc(Cl)ccc2[Al]1C1CCN(CCCn2c(=O)[nH]c3ccccc32)CC1</smiles>

Figure I Chemical structures of the Domperidone.

(5-chloro-I-[I-[3-(2-oxo-2,3-dihydro-I H-benzimidazol-I-yl)propyl]-4 piperidinyl]-I,3-dihydro-2H benzimidazol-2-one).

Chemical Formula: $\mathrm{C}_{22} \mathrm{H}_{24} \mathrm{CIN}_{5} \mathrm{O}_{2}$

Molecular Weight: 425.92.

\section{Experimental}

\section{Materials and solutions}

Carbon steel with a chemical composition (weight \%) : C 0.15 , Mn 0.680, Si 0.230, Cr 0.077, S 0.016, Ni 0.59, Co 0.009, Ti 0.011, $\mathrm{Cu} 0.160$ and $\mathrm{Fe}$ balance was used in the corrosion tests. Prior to all measurements, the CS coins were abraded with different grades 
of emery papers up to 1200 grade, washed with bi-distilled water, degreased with acetone and dried in hot air blower, then kept in a desiccator for use.

All reagents were obtained from analytical reagent-grade. The aggressive $\mathrm{HCl}$ solution was prepared by dilution of $\mathrm{HCl}$ grade $37 \%$ with bi-distilled water. Domperidone drug was purchased from Cilag -Janssen Pharmaceutics (Belgium, Beerse) and used as received.

\section{Weight loss method}

Coins were measured $2 \times 2 \times 0.2 \mathrm{~cm}$ dimensions are utilized for weight loss tests, dipped in the corrosive solution $(100 \mathrm{ml} \mathrm{HCl})$ with and without different concentrations of the drug in the temperature range $25-55^{\circ} \mathrm{C}$. Three measurements were made in each case and the average value of the weight loss was taken in order to obtain best reproducibility. The inhibition efficiency (\% IE) and $(\theta)$ were measured utilized equation $1^{22}$

$$
\% I E=100 \times \theta=100 \times\left[1-\left(W_{\text {inh }} / W_{\text {free }}\right)\right]
$$

Where $\mathrm{W}_{\text {inh }}$ and $\mathrm{W}_{\text {free }}$ are the mass reduction for CS attendance and lack of the drug in solution of $\mathrm{HCl}$ and $\theta$ is the degree of coverage surface for drug.

\section{Electrochemical measurements}

A conventional cell of capacity $100 \mathrm{ml}$ was used. It contains three compartments:

a. C-steel sample as a working electrode;

b. A platinum foil with $1 \mathrm{~cm}^{2}$ surface area was chosen as a counter electrode;

c. A saturated calomel electrode (SCE) via a Luggin capillary probe was used as a reference electrode. The working electrode was treated as before.

The electrochemical tests were done utilized Potentiostat/ Galvanostat/Zera analyzer (Gamry PCI 300/4). These contain Gamry framework organization created on the ESA400, and a PC with software DC 105 for PP, EIS software 300, and EFM software 140 Echem Specialist software 5.58 was utilized for drawing, graphing, and suitable value.

Tafel polarization was conducted from -600 to $-250 \mathrm{mV}$ at a sweep rate $1 \mathrm{mV} \mathrm{s}^{-1}$ to study the effect of drug on CS corrosion. Corrosion current density $\left(\mathrm{i}_{\text {corr }}\right)$ was determined by extrapolating the linear Tafel segments of anodic and cathodic curves to corrosion potential. The $\% \mathrm{IE}$ and $\theta$ were determined using the relationship:

$$
\% I E=\theta \times 100=\left[1-\left(i_{\text {corr }} / i_{\text {corr }}^{o}\right)\right] \times 100(2)
$$

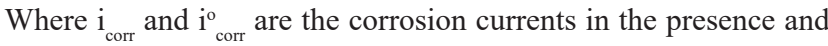
absence of the drug, respectively.

The EIS tests were conducted using AC signals of $10 \mathrm{mV}$ amplitude for the frequency spectrum from $100 \mathrm{kHz}$ to $0.1 \mathrm{~Hz}$ at OCP. The charge transfer resistance values were obtained from the diameter of the semicircles of the Nyquist plots. The \%IE and $\theta$ were calculated from the charge transfer resistance values using the following equation:

$$
\% I E=\theta \times 100=\left[1-\left(R_{c t}^{o}-R_{c t}\right)\right] \times 100(3)
$$

Where $\mathrm{R}^{\mathrm{o}}{ }_{\mathrm{ct}}$ and $\mathrm{R}_{\mathrm{ct}}$ are the charge-transfer resistances in absence and presence of the drug, respectively.
EFM measurements were conducted using the perturbation signals of frequencies 0.2 and $0.5 \mathrm{~Hz}$ with $20 \mathrm{mV}$ RMS amplitude. All tests have been given in solutions aerated at $25^{\circ} \mathrm{C}$. The $\% \mathrm{IE}$ and $\theta$ were calculated using Eq (2).

\section{Results and discussion}

\section{WL measurements}

In order to elucidate the influence of immersion time on the corrosion rate of CS, the data as shown in Figure 1 the WL of CS enhances with immersion time and by increasing the dose of Domperidone, the WL of CS samples are decreased indicating that the corrosion rate of Domperidoneis decreased. ${ }^{23}$ On other hand, Domperidone inhibits the corrosion process by adsorbing at the solution / metal interface. The increased IE and lower corrosion rate might be due to the improved adsorption and rise $(\theta)$ of drug on surface of CS with dose rise. The maximum IE of Domperidone reached $94.7 \%$ and was achieved at 1.12 $\mathrm{X} 10^{-4} \mathrm{M}$ at $25^{\circ} \mathrm{C}$ after immersion time 30 minutes. Table 2 revealed that the data of the IE increased with increasing Domperidone doses (Figure 2).

\begin{tabular}{|c|c|c|c|c|c|c|c|}
\hline $\begin{array}{l}\text { Conc, } \\
M\end{array}$ & $\begin{array}{l}\text { I M } \\
\mathrm{HCl}\end{array}$ & $\begin{array}{l}7 \times \\
10-6\end{array}$ & $\begin{array}{l}1.4 x \\
10-5\end{array}$ & $\begin{array}{l}2.8 \times \\
10-5\end{array}$ & $\begin{array}{l}5.6 \times \\
10-5\end{array}$ & $\begin{array}{l}8.4 x \\
10-5\end{array}$ & $\begin{array}{l}1.12 \times \\
10-4\end{array}$ \\
\hline \%IE & ----- & 70 & 78.3 & 82.4 & 86.9 & 90.8 & 94.7 \\
\hline
\end{tabular}

Table 2 Variation of \%IE with concentration of Domperidone in IM $\mathrm{HCl}$ at $25^{\circ} \mathrm{C}$ after immersion time $30 \mathrm{~min}$

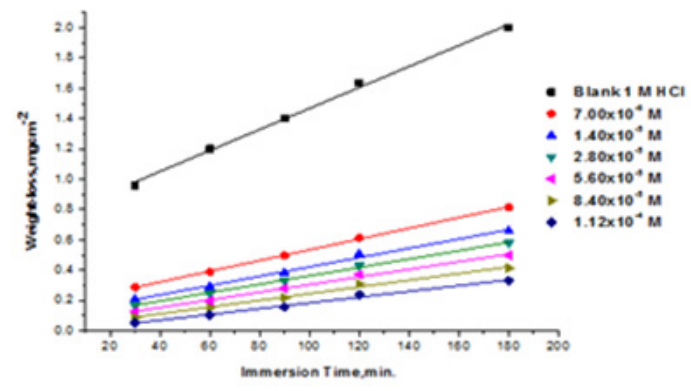

Figure $2 \mathrm{WL}$ vs. time for $\mathrm{CS}$ in $\mathrm{IM} \mathrm{HCl}$ with and without different doses of Domperidone at $25^{\circ} \mathrm{C}$.

\section{Temperature effect on IE}

Temperature has a strong influence on the phenomenon of corrosion. Figure 3 represents the effect of temperature on the IE of the Domperidonedrug at different doses. The results are shown in Table 3. The data revealed that the IE lowered by improving the temperature, because the desorption of drug molecules from the CS surface.

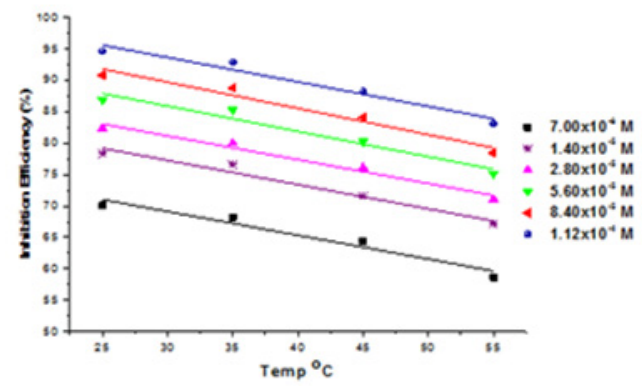

Figure 3 (log CR Vs. 1000/T) for CS in IM HCl with and without various doses of Domperidone drug. 
Table 3 The temperature effect on the IE of the Domperidone at various doses after 30 min immersion

\begin{tabular}{lllll}
\hline Inhibitor $\mathbf{M}$ & \% IE & & & \\
\hline & 250C & 35oC & 45oC & 55oC \\
\hline $7.0 \times 10-6$ & 70 & 68.2 & 64.4 & 58.7 \\
$1.4 \times 10-5$ & 78.3 & 76.6 & 71.5 & 67.2 \\
$2.8 \times 10-5$ & 82.4 & 80 & 76.1 & 71.1 \\
$5.6 \times 10-5$ & 86.9 & 85.3 & 80.2 & 75.2 \\
$8.4 \times 10-5$ & 90.8 & 88.8 & 84.1 & 78.5 \\
$1.12 \times 10-4$ & 94.7 & 92.9 & 88.3 & 83.2
\end{tabular}

\section{Kinetic study}

Corrosion rate data obtained from the WL tests for CS with and without various doses of Domperidonedrug was utilized to measure the, $\mathrm{E}^{*}{ }_{\mathrm{a}}$, entropy, $\Delta \mathrm{S}^{*}{ }_{\mathrm{a}}$ and enthalpy of activation, $\Delta \mathrm{H}^{*}{ }_{\mathrm{a}}$ from the following equations:

$$
\log C R=\left(E_{a}^{*}\right) / R T+A(4)
$$

and its formulation alternative named transition state equation:

$$
C R=R T /\left(N h \exp \Delta S_{a}^{*} / R\right) \exp \left(-\Delta H^{*}{ }_{a} / R T\right)
$$

Where $\mathrm{CR}=$ Rate of Corrosion, $\mathrm{R}=$ Constant for Universal Gas, $\mathrm{A}=$ Factor Arrhenius Pre Exponential, $\mathrm{T}=$ Temperature Absolute, $\mathrm{N}=$ Number of Avogadro's and $\mathrm{h}=$ Planck's Constant. The data of $\mathrm{E}^{*}{ }_{\mathrm{a}}$, were measured from Figure 3 and the data of $\Delta \mathrm{H}^{*}{ }_{\mathrm{a}}$ and $\Delta \mathrm{S}^{*}$ were measured from Figure 4. The measured data of the $\mathrm{E}^{*}$, $\Delta \mathrm{S}^{*}{ }^{\mathrm{a}}$ and $\Delta \mathrm{H}^{*}$ are listed in Table 4 . These values led to the presence of Domperidonedrug improve the $\mathrm{E}_{\mathrm{a}}^{*}$. The increase values of $\mathrm{E}^{*}{ }_{\mathrm{a}}$ in the presence of Domperidonedrug than in its absence is attributed to the physisorption adsorption. ${ }^{24}$ The values of $\mathrm{E}^{*}$ is ranging from 37.6 to $60.8 \mathrm{~kJ} \mathrm{~mol}^{-1}$ can be offer to the physical adsorption. ${ }^{25}$ The positive sign of $\Delta \mathrm{H}^{*}$, reveals that the dissolution process of CS is endothermic one. Usually, the enthalpy of physical adsorption process is small than $40 \mathrm{~kJ} \mathrm{~mol}^{-1}$ while the enthalpy of chemisorption reach $100 \mathrm{~kJ} \mathrm{~mol}^{-1}$. Hence, the $\Delta \mathrm{H}^{*}{ }_{\mathrm{a}}$ values obtained confirm the physical adsorption of Domperidonemolecule on the surface of CS. All $\mathrm{E}^{*}{ }_{\mathrm{a}}$ data are higher than the analogous value of $\Delta \mathrm{H}^{*}$ a indicate the process of corrosion include a gaseous reaction, simply evolution hydrogen reaction, associated with a break down in total volume ${ }^{26}$. We remark that $\mathrm{E}^{*}$ and $\Delta \mathrm{H}^{*}$ data vary in similar way with the drug dose this result permits to verify the known thermodynamic among $\mathrm{E}^{*}$ and $\Delta \mathrm{H}^{*}{ }_{\mathrm{a}}$ characterizing unimolecular reaction: ${ }^{27}$

$$
E_{a}^{*}-\Delta H_{a}^{*}=R T(6)
$$

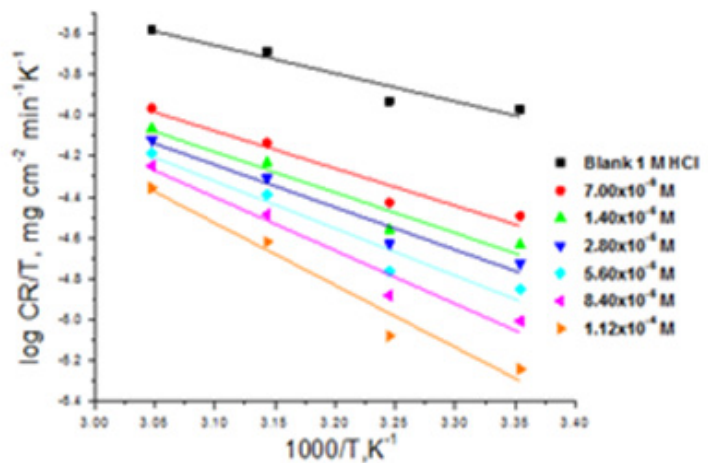

Figure $4(\log C R / T$ Vs. 1000/T) for CS in IM HCl with and without different doses of Domperidone drug.

\begin{tabular}{|c|c|c|c|c|}
\hline Conc, M & $\begin{array}{l}-\Delta \mathbf{S} * \mathbf{a} \text { J } \\
\text { mol- I K-I }\end{array}$ & $\begin{array}{l}\Delta \mathbf{H}^{*} \mathbf{a} \text { J } \\
\text { mol-I K-I }\end{array}$ & $\begin{array}{l}\text { E*a J } \\
\text { mol-I K-I }\end{array}$ & $\begin{array}{l}\mathbf{E} * \mathbf{a}- \\
\Delta \mathbf{H}^{*} \mathbf{a}\end{array}$ \\
\hline $\mathrm{IM} \mathrm{HCl}$ & 186 & 26.26 & 28.87 & 2.61 \\
\hline $7 \times 10-6$ & 167 & 34.97 & 37.58 & 2.62 \\
\hline $1.4 \times 10-5$ & 159 & 37.96 & 40.58 & 2.62 \\
\hline $2.8 \times 10-5$ & 155 & 39.78 & 42.4 & 2.62 \\
\hline $5.6 \times 10-5$ & 143 & 44.19 & 46.81 & 2.62 \\
\hline $8.4 \times 10-5$ & 127 & 49.84 & 52.46 & 2.62 \\
\hline $1.12 \times 10-4$ & 10 & 58.16 & 60.79 & 2.63 \\
\hline
\end{tabular}

Table 4 Activation parameters for CS dissolution with and without various doses of Domperidone drug in $\mathrm{IM} \mathrm{HCl}$

The measured data are too near to RT is $2.62 \mathrm{~kJ} \mathrm{~mol}^{-1}$. This result given the inhibitor play equally on $\mathrm{E}^{*}$ and $\Delta \mathrm{H}^{*}{ }_{\mathrm{a}}$. The negative sign of $\Delta \mathrm{S}^{*}$ lead higher order produced during the activation process. This can be achieved by the formation of activated complex and represents association rather than the dissociation step. ${ }^{28}$

\section{Adsorption isotherms study}

Adsorption isotherm is important to research the mechanism of reaction and also the characteristics of adsorption. Usually information about the kind of adsorption physisorption, chemisorption or comprehensive adsorption of the inhibitor on the CS surface, the tested value have been occurred with many adsorption isotherms to fit surface coverage value to classical isotherms of Frumkin, Temkin, Langmuir, and kinetic-thermodynamic isotherms. The Domperidonedrug adsorptions on the CS follow Langmuir adsorption isotherm and kinetic-thermodynamic model.

Langmuir adsorption isotherm: Figure $5 \& 6$ give the relation among $\mathrm{C} / \theta$ and $\mathrm{C}$ of the Domperidonedrug in $\mathrm{HCl}$ on the $\mathrm{CS}$ surface (isotherm Langmuir). Langmuir adsorption model postulates ${ }^{29}$ that:

i. There is no reaction among the molecules adsorbed,

ii. The energy of adsorption not depends on $(\Theta)$ and

iii. Maximum adsorption corresponds to the saturated monolayer.

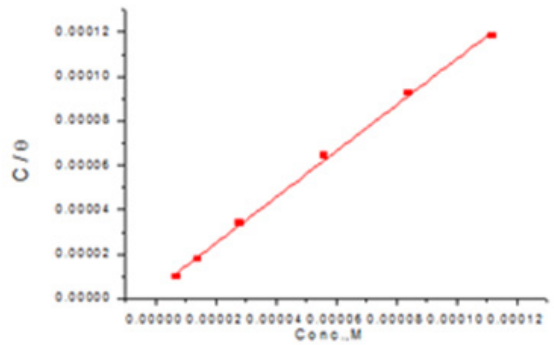

Figure 5 Langmuir isotherm plotted as $\mathrm{C} / \Theta$ vs. Conc. of Domperidone drug for the corrosion of $\mathrm{CS}$ in $\mathrm{IM} \mathrm{HCl}$ at $25^{\circ} \mathrm{C}$.

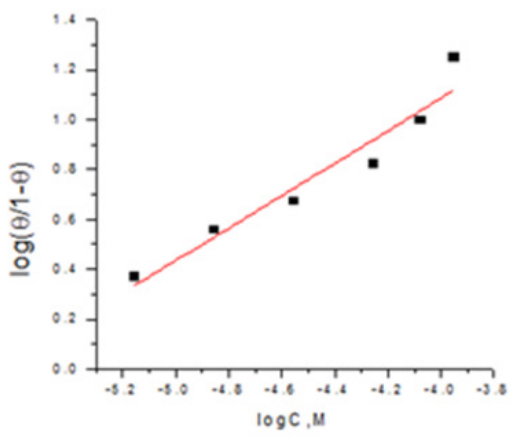

Figure 6 Kinetic model plotted as $\log (\Theta / I-\Theta)$ vs. $\log C$ of Domperidone drug for the $\mathrm{CS}$ corrosion in $\mathrm{IM} \mathrm{HCl}$ at $25^{\circ} \mathrm{C}$. 
The Langmuir equation can be described by equation (7) indicating that only one molecule could be adsorbed on one adsorption site.

$$
C / \theta=1 / K_{\text {ads }}+C(7)
$$

Where $\Theta=$ Degree of Coverage, $C=$ Drug Dose in the Bulk of Solution and $\mathrm{K}_{\mathrm{ads}}=$ Constant Equilibrium for the Adsorption Process, which given from the intercept of the lines and its data is illustrated in Table 5 and it is due to the $\left(\Delta \mathrm{Go}_{\text {ads }}\right)$ by follow:

$$
K_{\text {ads }}=1 / 55.5 \exp \left(-\Delta G_{\text {ads }}^{o} / R T\right)
$$

Table $5\left(\mathrm{~K}_{\mathrm{ads}}\right),\left(\Delta \mathrm{G}^{\circ}{ }_{\text {ads }}\right)$ and of active center number $(\mathrm{I} / \mathrm{y})$ and y number of inhibitor molecules occupying one active site for drug adsorbed of on CS at unlike

\begin{tabular}{|c|c|c|c|c|c|c|c|}
\hline \multirow[b]{2}{*}{ Temp oC } & \multicolumn{3}{|c|}{ Langmuir Isotherm } & \multicolumn{4}{|c|}{ Kinetic Model } \\
\hline & Kads x I04M-I & $-\Delta \mathbf{G}^{\circ}$ ads kJ mol- I & $\mathbf{R} \mathbf{L}$ & $\mathrm{I} / \mathrm{Y}$ & $\mathbf{Y}$ & $-\Delta \mathbf{G}^{\circ}$ ads $\mathbf{k J ~ m o l - I}$ & Kads x I04M-I \\
\hline 25 & 24.21 & 40.7 & 0.99 & 1.54 & 0.65 & 49 & 68.15 \\
\hline 35 & 22.86 & 41 & 0.99 & 1.53 & 0.65 & 44.7 & 63.24 \\
\hline 45 & 20.65 & 43 & 0.99 & 1.52 & 0.66 & 44.5 & 59.01 \\
\hline 55 & 18.36 & 44 & 0.99 & 1.51 & 0.66 & 44.3 & 53.56 \\
\hline
\end{tabular}
temperatures

Where 55.5=water molar dose in the solution. Besides, the fundamental characteristic isotherm Langmuir can be communicated in term of a dimensionless separation partition factor, $\mathrm{R}_{\mathrm{L}}{ }^{30}$, which describes the kind of isotherm and given by:

$$
R_{L}=1 /(1+K C)
$$

The lower $R_{L}$ data led to maximum adsorption favorable. If $R_{L}>1$ unfavorable, $0<\mathrm{R}_{\mathrm{L}}<1$ favorable $\mathrm{R}_{\mathrm{L}}=1$ linear, and if $\mathrm{R}_{\mathrm{L}}=0$ irreversible. ${ }^{31}$ Table 5 shows the estimated data of $\mathrm{R}_{\mathrm{L}}$ for Domperidonedrug at various dose and unlike temperatures. It was found that all $\mathrm{R}_{\mathrm{L}}$ data are less than unity conforming that the adsorption processes is favorable i.e. its fixation capacity grows rapidly with dose in equilibrium in liquid phase.

\section{Kinetic thermodynamic model}

According to the kinetic thermodynamic model the adsorption isotherm relationship is represented by the equation (10):

$$
\log (\theta / 1-\theta)=y \log C+\log K^{\backslash}(10)
$$

Where $y=$ number of molecules drug presence on active center of the metal surface and $1 / y=$ number of active center made by one drug molecule. Values of $y>1$ implies the formation of multilayers of drug on the surface of CS. Data of $y<1$ mean a drug molecules obtain will occupy more than one active center.

Table 5 reveals that the data of $\mathrm{K}_{\text {ads }}$ lower by temperature rise, this lead to the binding power of the drug to the metal surface lower with raising temperature. Such habit can be interpreted on the basis that improve temperature results in desorption of some molecules of the Domperidonefrom the metal surface ${ }^{32}$. Maximum data of $\mathrm{K}_{\text {ads }}$ mean excellent protection efficiency of the inhibitor, i.e., higher electrical interaction among the adsorbing molecules and presence of double-layer at the boundary phase.

The data of the $\Delta \mathrm{G}^{\circ}$ ads in most samples are negative. The $-\mathrm{ve}$ data signify a spontaneous adsorption of the drug molecules and stability of the adsorption layer. Usually, data of $\Delta \mathrm{G}_{\text {ads }}^{\circ}$ up to $-20 \mathrm{~kJ}$ $\mathrm{mol}^{-1}$ are consistent with electrostatic reaction among a charged metal and molecules(which given physical adsorption) while those more negative than $-40 \mathrm{~kJ} \mathrm{~mol}^{-1}$ contain charge sharing or change from the inhibitor molecules to the surface of metal to form a coordinate kind bond, which given chemisorptions. ${ }^{33}$ Outcome attendance in Table 5 led to that the data of $\Delta \mathrm{G}^{\circ}$ ads for all models studied lie between -40.7 and $-45.9 \mathrm{~kJ} \mathrm{~mol}^{-1}$, given the mechanism of adsorption by Domperidonetested may be mixed one (chemisorption and physisorption). The values of $\Delta \mathrm{H}^{\mathrm{o}}$ ads obtained by plot of $\mathrm{Ln}$
$\mathrm{K}_{\text {ads }}$ against $1000 / \mathrm{T}$ the slope of the straight line is $\left(-\Delta \mathrm{H}^{\circ}\right.$ ads $\left./ \mathrm{R}\right)$. In the present case; the values of $\Delta \mathrm{H}^{\mathrm{o}}{ }_{\text {ads }}$ obtained in this study was $-7.5 \mathrm{~kJ}$ $\mathrm{mol}^{-1}$ and lower than $(40 \mathrm{~kJ} \mathrm{~mol}-1)$, this indicative of physisorption. ${ }^{34}$ Moreover, physisorption was judging from the lower of \%IE with temperature improves.$^{35}$ From represent obtained results indicate that the process of inhibition used in this reaction is mixed physisorption and chemisorptions process.

But, values of other thermodynamic parameter as $\Delta \mathrm{H}^{\circ}$ ads can supplementary knowledge about the corrosion protection mechanism. Generally -ve data of $\Delta \mathrm{H}^{\circ}$ ads led to that the adsorption of drug is an exothermic while a positive value of $\Delta \mathrm{H}^{\circ}$ ads is endothermic. Generally, an exothermic process signifies either physisorption or chemisorption while process endothermic is unequivocally attributable to chemisorptions. $^{36}$ In an exothermic process, physisorption is characteristic from chemisorption by considering the absolute data of $\Delta \mathrm{H}^{\circ}$ ads for the physisorption process which is breck down than $40 \mathrm{~kJ}$ mol-1 while that for chemisorption process arrive to $100 \mathrm{~kJ} \mathrm{~mol}-1 .{ }^{37}$ Van't Hoff equation was utilized to get more $\Delta \mathrm{H}^{\circ}$ ads adsorption enthalpy.

$$
L n K_{a d s}=\left(-\Delta H_{a d s}^{o} / R T\right)+\text { constant }(12)
$$

\section{PP measurements}

The anodic and cathodic PP curves of the $\mathrm{CS}$ in $1 \mathrm{M} \mathrm{HCl}$ with and without various doses of Domperidonedrug are shown in Figure 7. Electrochemical corrosion kinetic parameters obtained by PP method such as current corrosion densities $\left(\mathrm{i}_{\text {corr }}\right)$, corrosion potentials $\left(\mathrm{E}_{\text {corr }}\right)$, Tafel slopes cathodic and anodic $\left(b_{c}\right),\left(b_{a}\right)$ and protection efficiency $\% \mathrm{IE}$ are illustrated in Table 6. The corrosion current and corrosion rate decreased with increasing Domperidone, consequently, the inhibition efficiency increases, reaching a maximum value of $94.9 \%$ at $1.12 \times 10^{-4} \mathrm{M}$ of Domperidone. This is due to the blocked fraction of the metal surface by adsorption, this can be attributed to the presence of electron-donating groups ( $\pi$-electrons on aromatic ring, $\mathrm{O}, \mathrm{N}$ ) in Domperidonethat can react with the metal surface and protect it from the attack. ${ }^{38}$ The obtained data revealed that addition of Domperidonein $1 \mathrm{M} \mathrm{HCl}$ solution lower the anodic dissolution of $\mathrm{CS}$ and also prevent the cathodic hydrogen evolution reaction. Also, the shift in $E_{\text {corr }}$ from the blank solution was about $13 \mathrm{mV}$ less than $85 \mathrm{mV}$, indicating that Domperidoneplays as a mixed-type inhibitor, ${ }^{39}$ in addition to the values of $b_{a}$ and $b_{c}$ are approximately constant. Thus protection of corrosion in $1 \mathrm{M} \mathrm{HCl}$ solution is merely due to the blocking of surface active sites by adsorption.

EIS tests: The results obtained can be illustrated in terms of the equivalent circuit (Figure 8) which was utilized with preceding 
model the C/acid interface. ${ }^{40}$ Figure $9 \mathrm{a} \& \mathrm{~b}$ displays the Nyquist (a) and Bode (b) digrams for $\mathrm{CS}$ in solution of $\mathrm{HCl}$ with and without various doses of Domperidonedrug. Figure 9a shows; the semicircle with drug is higher than that in the Blank. Figure $9 \mathrm{~b}$ shows the Bode plots which gave only one capacitive time constant and one well resolved peak. The electrochemical parameters were calculated and are listed in Table 7 which indicates that the charge transfer resistance $\left(\mathrm{R}_{\mathrm{ct}}\right), \% \mathrm{IE}$ increased while double layer capacitance $\left(\mathrm{C}_{\mathrm{d} 1}\right)$ is decreased by increasing Domperidonedose. This is due to the lower in local dielectric constant and/or an increase in the electrical double layer thickness, suggesting that Domperidonemolecules function by solution/interface adsorption. ${ }^{41}$ It could be assumed that the lower of $\mathrm{C}_{\mathrm{dl}}$ data is caused by the replacement gradual of water molecules by adsorption of Domperidonemoleculeson the surface of electrode, which lower the extent of dissolution.

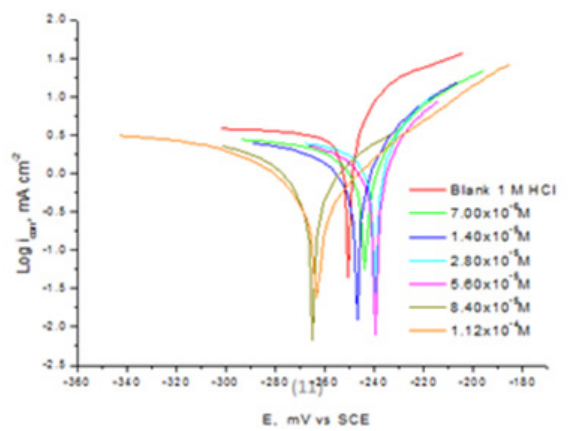

Figure 7 Potentiodynamic polarization curves recorded for CS in IM HCl solution with and without various doses of Domperidone at $25^{\circ} \mathrm{C}$.

Table 6 Electrochemical parameters given from polarization curves for CS in IM HCl with and without various doses of Domperidone at $25^{\circ} \mathrm{C}$

\begin{tabular}{|c|c|c|c|c|c|c|}
\hline Inh,,$M$ & -Ecorr, mVvs SCE & icorr, mA cm-2 & \%IE & CR mmy-I & ba $\mathrm{mV}$ dec-I & -bc mV dec-I \\
\hline I $\mathrm{M} \mathrm{HCl}$ & & 11.4415 & ---- & & & \\
\hline $7.0 \times 10-6$ & 244 & 3.4291 & 70 & 40.1 & 60 & 69 \\
\hline $1.4 \times 10-5$ & 247 & 2.4975 & 78.2 & 29.21 & 51 & 120 \\
\hline $2.8 \times 10-5$ & 239 & 1.9517 & 82.9 & 22.82 & 30 & 117 \\
\hline $5.6 \times 10-5$ & 240 & 1.5116 & 86.8 & 17.67 & 33 & 111 \\
\hline $8.4 \times 10-5$ & 265 & I.0803 & 90.6 & 12.63 & 69 & 111 \\
\hline $1.12 \times 10-4$ & 263 & 0.5894 & 94.9 & 6.89 & 47 & 67 \\
\hline
\end{tabular}

Table 7 Impedance parameters for CS corrosion with and without various doses of Domperidone drug at $25^{\circ} \mathrm{C}$

\begin{tabular}{|c|c|c|c|c|}
\hline Conc, $M$ & Rp, ohm cm2 & Cdl, $x \mid 0-5 \mu F \mathrm{~cm}-2$ & $\boldsymbol{\theta}$ & \%IE \\
\hline $\mathrm{I} \mathrm{M} \mathrm{HCl}$ & 36.81 & 167.6 & ---- & ----- \\
\hline $7.0 \times 10-6$ & 129.3 & 161 & 0.715 & 71.5 \\
\hline $1.4 \times 10-5$ & 173.8 & 129.6 & 0.788 & 78.8 \\
\hline $2.8 \times 10-5$ & 216.6 & 89.4 & 0.83 & 83 \\
\hline $5.6 \times 10-5$ & 291 & 84.9 & 0.874 & 87.4 \\
\hline $8.4 \times 10-5$ & 409.5 & 80.7 & 0.91 & 91 \\
\hline $1.12 \times 10-4$ & 696.8 & 63 & 0.947 & 94.7 \\
\hline
\end{tabular}

Table 8 EFM spectra of CS corrosion with and without various doses of Domperidone drug at $25^{\circ} \mathrm{C}$

\begin{tabular}{|c|c|c|c|c|c|c|c|}
\hline Conc, M & icorr. $\mu \mathrm{A} \mathrm{cm}-2$ & Ba mVdec-I & $-\beta c$ mVdec-I & CR mpy & CF-2 & CF-3 & $\%$ IE \\
\hline Blank & 470.1 & 91 & 106 & 214.8 & 2.02 & 3.5 & ----- \\
\hline $7 \times 10-6$ & 133.5 & 86 & 125 & 61 & 1.94 & 3.43 & 71.6 \\
\hline $2.8 \times 10-5$ & 83.98 & 81 & 121 & 38.37 & 2.02 & 5.74 & 82.2 \\
\hline $5.6 \times 10-5$ & 57.56 & 107 & 115 & 26.3 & 1.92 & 1.74 & 87.8 \\
\hline $8.4 \times 10-5$ & 38.7 & 79 & 86 & 17.68 & 1.91 & 2.41 & 91.8 \\
\hline
\end{tabular}

\section{EFM tests}

The EFM is a non-destructive corrosion tests that can directly give data for the current of corrosion without prior information of Tafel constants. ${ }^{42}$ The measured parameters of corrosion kinetic at various doses of the Domperidonedrug in $1 \mathrm{M} \mathrm{HCl}$ at $25^{\circ} \mathrm{C}$ are given in Table 8 which revealed that, the corrosion $\mathrm{i}_{\text {corr }}$ break down and the IE improve by improvement dose of Domperidone. The higher EFM strength is the causality factor, which act as an internal check on the EFM validity. ${ }^{43}$ The standard value for CF-2 and CF-3 are 2.0 and 3.0 , continually. The causality factors deviation from their ideal data might due to that the amplitude perturbation was too lower or that the frequency spectrum resolution is not enough high.

\section{AFM analysis}

The advantage of this method is that the roughness of the surface can be determined. Figure 10a shows 3d AFM image of CS coins before immersion in the corrosive medium with roughness $14.1 \mathrm{~nm}$. Figure 10b is an image obtained for CS coins after immersion in $1 \mathrm{M}$ $\mathrm{HCl}$ solution with roughness $392.6 \mathrm{~nm}$. Figure $10 \mathrm{c}$ is the image of $\mathrm{CS}$ after immersion in $1 \mathrm{M} \mathrm{HCl}+300 \mathrm{ppm}$ of drug with roughness $289.0 \mathrm{~nm}$. The lower value of roughness in the presence of drug as compared to its absence indicates the adsorption of drug molecules on CS surface, and hence inhibit the corrosion process.

\section{Mechanism of in inhibition}

Generally, Corrosion inhibition mechanism in acid medium is the adsorption of inhibitor onto the metal surface. As far as the inhibition process is concerned, it is generally assumed that adsorption of the inhibitor at the metal/solution interface is the first step in the action mechanism of the inhibitors in aggressive acid media. Four types of adsorption may take place during inhibition involving organic molecules at the metal/solution inter-face: ${ }^{44}$ electrostatic attraction 
between charged molecules and the charged metal, ${ }^{45}$ interaction of unshared electron pairs in the molecule with the metal, ${ }^{46}$ interaction of $\pi$-electrons with the metal, and a combination of the above. ${ }^{47}$ The extent of adsorption of an inhibitors depended on the number of adsorption sites and their charge density, molecular size, heat of hydrogenation, mode of interaction with the metal surface, and the formation metallic complexes. ${ }^{48}$

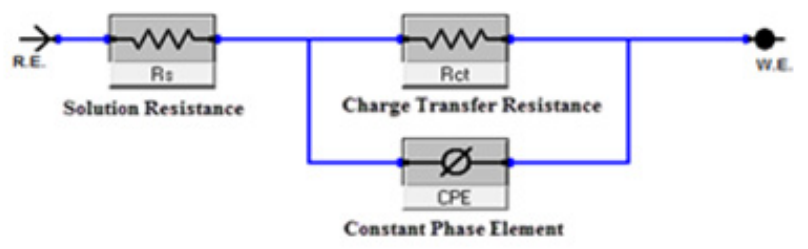

Figure 8 Circuit model utilized to fit test EIS value.
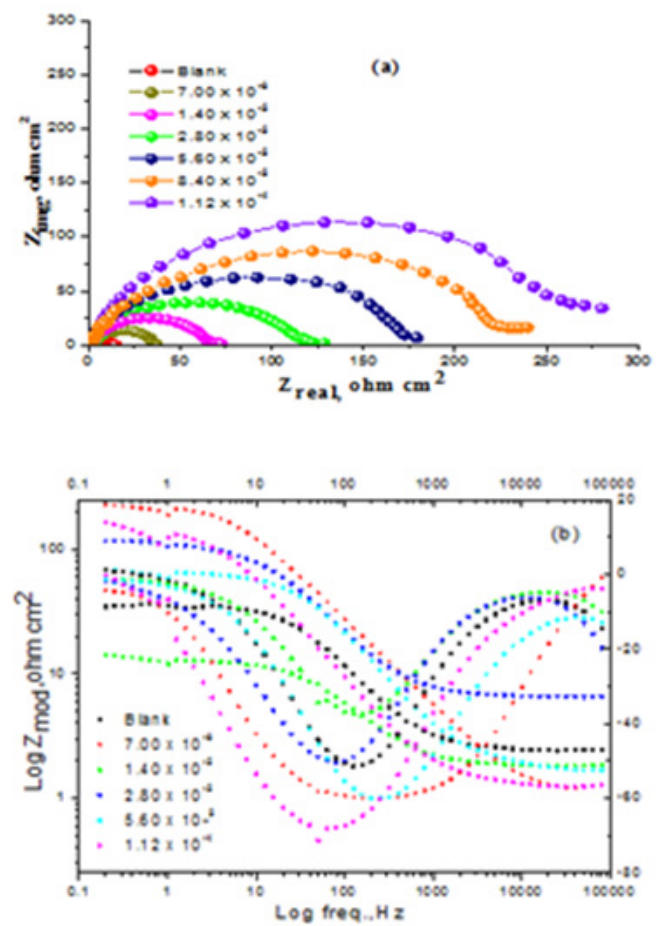

Figure 9 Nyquist (a) and Bode (b) curves for corrosion of CS with and without various doses of Domperidone at $25^{\circ} \mathrm{C}$.

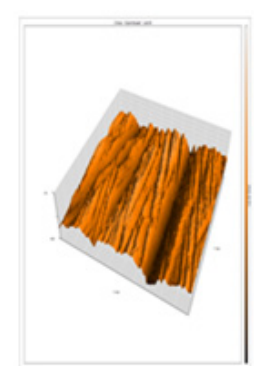

(a)

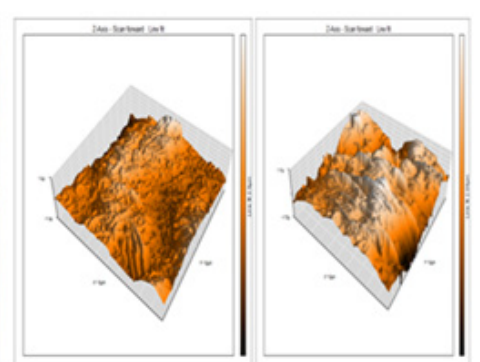

(b) (c)
Figure I0 AFM 3D images of CS (a) free specimen (b) in IM HCl for $12 \mathrm{hrs}$ (c) in $1 \mathrm{M} \mathrm{HCl}$ containing $1.6 \times 10^{-4} \mathrm{M}$ for $12 \mathrm{hrs}$. Domperidone drug at $25^{\circ} \mathrm{C}$.

The inhibitory action of Domperidonedrug may be due to any or combination of the above mechanisms. The higher IE may be due to the large molecular weight of the compound which covered wider surface of the CS. Corrosion inhibition of CS in $1 \mathrm{M} \mathrm{HCl}$ by Domperidonedrug can be explained on the basis that the CS surface acquires positive charge in the acid medium. ${ }^{49}$ It is believed that the $\mathrm{Cl}$ - ions could be specifically adsorbed on the metal surface and creates an excess of negative charge on the surface, then the protonated Domperidonecan be in the acid medium.

\section{Conclusion}

The outcome given from various tests such as WL, PP, EIS, EFM, measurements and FT-IR showed that Domperidonedrug protect corrosion of $\mathrm{CS}$ in molar $\mathrm{HCl}$ and results obtained from this study are reproducible. It exhibited a maximum inhibition efficiency mean value obtained from our different measurements of $94.8 \%$ at $1.12 \times 10<$ sup $>-4</$ sup $>$ concentration. Tafel curves give that Domperidoneis a mixed kind. The inhibition of CS corrosion by Domperidone can be attributed to the adsorption ability of drug molecules onto the reactive sites of the metal surface. The process of inhibition used in this reaction is mixed physisorption and chemisorptions process. The Domperidone improve the time needed for $\mathrm{CS}$ to consume half of its original amount.IR results indicate the formation of a protective film contains [Fe(II)/Fe(III)- Domperidone.

\section{Acknowledgments}

None.

\section{Conflicts of interest}

Author declares there are no conflicts of interest.

\section{Funding}

None.

\section{References}

1. Quraishi MA, Sardar R. Aromatic Triazoles as Corrosion Inhibitors for Mild Steel in Acidic Environments. Corrosion Science. 2002;58(9):748-755.

2. Juttner K. Electrochim Acta . 1990;35:1501-5108.

3. Quraishi MA, Sardar R, Jamal D. Mater Chem Phys. 2011;71:309-313.

4. Prabhu RA, Shanbhag AV, Venkatesha TV. Influence of tramadol [2-[(dimethylamino)methyl]-1-(3-methoxyphenyl) cyclohexanol hydrate] on corrosion inhibition of mild steel in acidic media. Journal of Applied Electrochemistry. 2007;37(4):491-497.

5. Eddy NO, Ebenso EE . Adsorption and Quantum Chemical Studies on Cloxacillin and Halides for the Corrosion of Mild Steel in Acidic Medium. Int J Electrochem Sci . 2010;5:731-750.

6. Morad MS. Corrosion Science . 2008;50:436-448.

7. Tuken T, Yazıcı B, Erbil M. The Effect of Nicotinamide on Iron Corrosion in Chloride Solutions. Turk J Chem. 2002;26:735-742.

8. Abdallah M. Corrosion Science. 2004;46:1981-1996.

9. Fouda AS, Al-Sarawy AA, Sh F Ahmed, et al. Corros Sci . 2009;51:485-492.

10. Zayed MA, Abdallah SM. Spectrochim Acta Part A Mol Biomol Spectrosc . 2004;60:2215-2224.

11. Karthik G, Sundaravadivelu M. Inhibition of Mild Steel Corrosion in Sulphuric Acid Using Esomeprazole and the Effect of Iodide Ion Addition. ISRN Electrochemistry. 2013; 2013(2013):403542.

12. Eddy NO, Odoemelam SA, Ekwumemgbo P. Inhibition of the corrosion of mild steel in $\mathrm{H}_{2} \mathrm{SO}_{4}$ by penicillin G. Sci Res Essays. 2009;4(1):033-038. 
13. Eddy NO, Odoemelam SA. Inhibition of the corrosion of mild steel in acidic medium by penicillin V potassium. Advances in Natural and Applied Sciences . 2008;2(3):225-232.

14. Singh AK, Quraishi MA. Effect of cefazolin on the corrosion of mild steel in $\mathrm{HCl}$ solution. Corrosion Science. 2010;52(1):152-160.

15. Shukla SK, Quraishi MA. Ceftriaxone: a novel corrosion inhibitor for mild steel in hydrochloric acid. Journal of Applied Electrochemistry. 2009;39(9):1517-1523.

16. Shukla SK, Quraishi MA. Cefotaxime sodium: a new and efficient corrosion inhibitor for mild steel in hydrochloric acid solution. Corrosion Science. 2009;51:1007-1011.

17. Naqvi I, Saleemi AR, Naveed S. Cefixime: a drug as efficient corrosion inhibitor for mild steel in acidic media. Electrochemical and thermodynamic studies. Int J Electrochem Sci . 2011;6(2011):146-161.

18. Singh AK, Quraishi MA. Adsorption properties and inhibition of mild steel corrosion in hydrochloric acid solution by ceftobiprole .Journal of Applied Electrochemistry. 2011;41(1):7-18.

19. Ebenso EE, Obot IB, Murulana LC. Quinoline and its derivatives as effective corrosion inhibitors for mild steel in acidic medium. Int $J$ Electrochem Sci . 2010;5(2010):1574-1586.

20. Singh A, Singh AK, Quraishi MA. Dapsone: a novel corrosion inhibitor for mild steel in acid media. The Open Electrochemistry Journal . 2010;2:43-51.

21. Dan Wang, Bin Xiang, Yuanpeng Liang, et al. Corrosion control of copper in 3.5 wt.\% NaCl Solution by Domperidone: Experimental and Theoretical Study. Corrosion Science. 2014;85:77-86.

22. Fouda A, Mostafa H, El-Abbasy H. Three-dimensional lithium manganese phosphate microflowers for lithium-ion battery applications. Journal of Applied Electrochemistry. 2012;40(3):163-167.

23. Abdallah M, Zaafarany I, Al-Fahemi J, et al. Antibacterial Cephalosporin as Inhibitors for the Corrosion of Iron in Hydrochloric Acid Solutions. Int J Electrochem Sci . 2012;7:6622-6637.

24. Bard A, Faulkner L. Electrochemical methods, fundamental and applications. Wiley, New York, USA. 1980. p.218.

25. Jorge S, Pontinha AR, Oliveira-Brett A. Electrochemical Redox Behavior of Omeprazole Using a Glassy Carbon Electrode. Electroanalysis. 2010;22(6):625-631.

26. Laviron E. J Electroanal Chem. 1979;101(19):28.

27. Martins I, Cristiani F, Larissa S. Talanta . 2011;85(10):7.

28. Lodha S. Pharmaceut Rev. 2008
29. Singh A, Quraishi M. Corrosion Science. 2010;52:1373.

30. Chen W, Luo HQ, Li NB. Corrosion Science 53:3356. 2011.

31. Desai M, Desai M. Corrosion Science. 1984;24:649.

32. Orubite-Okorosaye K, Oforka N. Corrosion Inhibition of Zinc on $\mathrm{HCl}$ using Nypa fruticans check for this species in other resources Wurmb Extract and 1,5 Diphenyl Carbazonen. J Appl Sci Environ. 2004;8(1):56-61.

33. Atkins P. Physical chemistry. In: Ebenso EE (Eds.). ( $7^{\text {th }}$ edn), Oxford press, Indai. 2002. p.79.

34. Sharma K, Sharma L. A textbook of physical chemistry. ( $4^{\text {th }}$ edn $)$, Vikas Pub House PVT Ltd, India. 2004.

35. Zhang Q, Hua Y. Mater Chem Phys . 2010;119:57.

36. Bouklah M, Hammouti B, Lagrenee M, et al. Corrosion Science. 2006; $48: 2831$

37. Fouda A, Abd El-Aal A, Kandil A. Desalination. 2006;201:216.

38. Umoren S, Obot I, Ebenso E. Corrosion Inhibition of Aluminium Using Exudate Gum from Pachylobus edulis in the Presence of Halide Ions in HCl. E-Journal of Chemistry. 2008;5(2):355-364.

39. Behpour M, Ghoreishi S. Corrosion Science. 2008;50:2172.

40. Samide A, Tutunaru B, Negrilab C. Corrosion Inhibition of Carbon Steel in Hydrochloric Acid Solution Using a Sulfa Drug. Chem Biochem Eng Q. 2011;25(3):299-308.

41. McCafferty E, Hackerman N. Double Layer Capacitance of Iron and Corrosion Inhibition with Polymethylene Diamines. J Electrochem Soc. 1972;119(2):146-154.

42. Bosch R, Hubrecht J, Bogaerts W, et al. Corrosion Science. 57:60

43. Bentiss F, Bouanis M, Mernari B, et al. Appl Surf Sci. 2007;253:3696.

44. Chao CY, Lin LF, Macdonald DD. A Point Defect Model for Anodic Passive Films. J Electrochem Soc. 1981;128(6):1187-1194.

45. Singh AK. Corrosion Science. 2010;52:152-160.

46. Abd El-Maksoud SS, Hassan HH. Electrochemical studies on the effect of (2E)-3-amino-2-phenylazo-but-2-enenitrile and its derivative on the behaviour of copper in nitric acid. Materials \& Corrosion . 2007;58(5):369-375.

47. LiSL, Wang YG, Chen SH, et al. Corrosion Science. 1999;41:1769-1782.

48. Schweinsberg D, George G, Nanayakkara A, et al. Corrosion Science 1988;28:33-42.

49. Driver R, Meakins R. Br Corros J . 1977;12(1):46. 